Revista Água Viva

\title{
O PAPA EM TEMPOS PANDÊMICOS: ANÁLISE DO DISCURSO DE FRANCISCO DURANTE A PANDEMIA DA COVID-19
}

\section{THE POPE IN PANDEMIC TIMES: ANALYSIS OF FRANCIS' SPEECH DURING THE COVID-19 PANDEMIC}

\author{
Gabriel Nogueira Linhares Marquim ${ }^{1}$
}

Recebido em: 16 jul. 2020

Aceito em: 24 nov. 2020

DOI: 10.26512/aguaviva.v5i3.32608

RESUMO: Este trabalho analisa o discurso mobilizado pelo papa Francisco em diferentes momentos durante a pandemia da Covid-19, que assolou todo o mundo. Através das abordagens teóricas e metodológicas da Análise do Discurso de linha francesa (AD), especialmente dos estudos de Pêcheux (1995, 1999) e comentadores, como Orlandi (2007), Mussalim e Bentes (2003) e Fernandes (2007), articulamos conceitos como ideologia, posição-sujeito, formações ideológicas e discursivas. Por fim, demonstramos como o pontífice articula suas formações discursivas, sendo elas "religiosa" e "política", dentro de sua visão poliédrica da realidade e do catolicismo.

Palavras-chave: Posição-sujeito. Formações discursivas. Religião. Papa Francisco.

ABSTRACT: This paper analyzes the speech mobilized by Pope Francis at different times during the Covid-19 pandemic, which devastated the whole world. Through the theoretical and methodological approaches of Discourse Analysis of the French line (AD), especially the studies of Pêcheux (1995, 1999) and commentators such as Orlandi (2007), Mussalim and Bentes (2003) and Fernandes (2007), we articulate concepts such as ideology, subject-position, ideological and discursive formations. Finally, we demonstrate how the pontiff articulates his discursive formations, being "religious" and "political", within his polyhedral view of reality and Catholicism.

Keywords: Subject-position. Discursive formations. Religion. Pope Francis.

\section{INTRODUÇÃO}

O ano de 2020 começou surpreendido por notícias de que na China se multiplicavam as contaminações por um novo coronavírus. Os primeiros casos haviam sido notificados ainda no

\footnotetext{
${ }^{1}$ Doutorando em Ciências da Religião pela Universidade Católica de Pernambuco (Unicap), desenvolve pesquisa sobre a representação midiática da Igreja Católica. Mestre em Comunicação pela Universidade Federal de Pernambuco (UFPE), e graduado em Comunicação Social/Jornalismo pela Unicap (2009). Atualmente, é professor do Centro Universitário Maurício de Nassau (UNINASSAU). É fundador e presidente da Comunidade dos Viventes e do Projeto Vincular. Atua principalmente nos seguintes temas: Teoria da Comunicação, Jornalismo, Religião e Sociologia. E-mail: gmarquim@gmail.com
} 
ano anterior (daí porque se fala em Covid-19), e em pouco tempo o vírus se espalhou de forma incontrolável. Inicialmente, os países não deram grande atenção à questão e resistiram a tomar medidas mais rígidas, algo que depois passou a ser inadiável.

A partir do final de janeiro, a Organização Mundial da Saúde (OMS) declarou que se tratava de uma epidemia com alcance internacional; porém, em 11 de março a instituição caracterizou a situação como uma pandemia, elevando o nível de emergência e mudando completamente a rotina de milhões de pessoas em todo o mundo, postas em quarentena, enquanto a política e a economia dos países, das formas mais diversas, procuraram responder aos desafios. De fato, segue em todo o planeta a maior crise dos últimos cem anos, que revela as intrincadas e complexas questões da atualidade, e vai interpelando os mais variados agentes sociais.

Entre eles está a religião. Como sabemos, a realidade social é uma construção simbólica de representações sociais, e segundo Peter Berger e Thomas Luckmann (2009), a partir do seu tratado sobre a sociologia do conhecimento, a religião tem um papel fundamental nesse processo. No fundo, justamente porque articula um conjunto de crenças sobrenaturais, a religião também influencia nos valores e comportamentos dos seres humanos, dando-lhes respostas metafísicas e incidindo nos seus cotidianos.

Como é de se esperar, neste momento de crise, a religião assume um papel basilar, conferindo esperança, procurando dar sentido e oferecendo caminhos para milhões de pessoas que creem ou, ainda que não creiam, veem nas religiões uma fonte de orientação. Ao mesmo tempo, também os fiéis tiveram sua rotina espiritual modificada, já que em dezenas de países os templos precisaram ser fechados a fim de que não houvesse aglomeração de pessoas, procurando diminuir os riscos de contaminação.

Seguiu-se, então, um movimento que se espalhou por todos os lugares: a profusão das transmissões de cultos e cerimônias através dos meios de comunicação social, mas sobretudo das novas mídias, principalmente das redes sociais. Em pouco tempo, as lideranças precisaram refazer suas estratégias de pregação e participação, adaptando-se a um momento completamente inédito e inusitado, já que o núcleo das religiões tende a ser a congregação dos fiéis reunidos em um mesmo lugar. Ao contrário disso, o espaço tornou-se virtual, quando, segundo Pierre Lévy (2010), as pessoas estão temporalmente presentes, mas espacialmente distantes.

Também a Igreja Católica precisou adaptar-se às mudanças, e isso está representado de forma emblemática nos discursos e gestos de sua liderança, o papa Francisco. De fato, o pontífice demonstrou que a pandemia teve uma repercussão não somente em sua rotina, mas 
também no seu ensinamento. Isso fica claro, por exemplo, quando o papa explicita a surpresa com a necessidade de transmitir suas mensagens através da internet, sem o contato direto com os católicos: “é um pouco estranho esta oração do Angelus hoje, com o papa 'fechado' na biblioteca" (FRANCISCO, 2020).

Nosso objetivo nas próximas páginas é analisar a maneira como Francisco articulou o seu discurso em tempos pandêmicos, intercalando formações discursivas distintas dentro de uma formação ideológica católica a fim de comunicar-se, como veremos, com os católicos, mas também com outros espectros sociais. Para isso, utilizaremos como ferramenta de trabalho a Análise do Discurso (AD) de linha francesa, aquela desenvolvida por Michel Pêcheux (1995, 1999) e outros pesquisadores que a desenvolveram, como Orlandi (2007), Mussalim e Bentes (2003), Fernandes (2007) e Brandão (2014).

$\mathrm{Na}$ primeira parte, abordaremos algumas das principais concepções da $\mathrm{AD}$, como sujeito, discurso, sentido, formações ideológicas e formações discursivas. Após isso, apresentaremos o nosso objeto de estudo, ou seja, os discursos proferidos pelo papa durante a pandemia, que serão depois analisados. Por fim, avaliaremos os principais resultados da nossa reflexão.

Acreditamos que, com isso, não somente entenderemos melhor as concepções de mundo do papa e da Igreja, mas lançaremos luzes sobre a maneira como o catolicismo compreendeu a pandemia e fez a sua representação neste momento difícil da História.

\section{A Análise do Discurso como teoria e método de investigação}

As relações sociais são o conjunto de relações interpessoais e estruturais, e estas são realizadas através da linguagem. De fato, no nosso cotidiano, somos permanentemente permeados por distintas comunicações, sejam elas orais ou não. Essa linguagem é realizada entre os falantes, que se expressam através de um discurso. Esse discurso, por sua vez, revela sentidos, que não estão definidos de forma monolítica, mas, ao contrário, dependem de quem os interpreta.

Justamente para investigar os intrincados meandros do discurso é que surgiu na França dos anos 1960 a Análise do Discurso. Originada em um período de fortes turbulências políticas, especialmente em 1968, a AD foi desenvolvida sobretudo através das pesquisas de Michel Pêcheux, que se utilizou do marxismo (especialmente da revisão de Althusser), da psicanálise (na releitura que Jacques Lacan fez da teoria de Sigmund Freud) e do estruturalismo linguístico (tomado de Ferdinand de Saussure). 
Através desse tripé, Pêcheux desenvolveu as suas noções dos principais conceitos que dão origem à AD: o sujeito, a ideologia, a formação ideológica, as formações discursivas e o sentido. Como se pode perceber, a $\mathrm{AD}$ não se restringe ao estudo linguístico em si, mas às condições de produção desse discurso, ou seja, aspectos extrínsecos à língua. Assim, é preciso estar atento, para se fazer uma boa análise, ao contexto sócio histórico em que se dá a elaboração do discurso, aos interlocutores envolvidos e também às ideologias que dão o substrato do discurso e que também ali se manifestam. Somente dessa maneira é possível alcançar aquilo que está para além do discurso em si.

É justamente nesse emaranhado de condições que o discurso será tecido, como explica o próprio Pêcheux:

diremos que as contradições ideológicas que se desenvolvem através da unidade da língua são constituídas pelas relações contraditórias que mantêm, necessariamente, entre si os "processos discursivos", na medida em que se inscrevem em relações ideológicas de classes (PÊCHEUX, 1995, p. 93).

Assim, não se pode conceber um sujeito que desenvolva o seu discurso sem a interferência de uma ideologia. Na verdade, um dos "lugares" privilegiados em que se pode encontrar a manifestação de uma ideologia é justamente no discurso, daí porque a AD trabalha com a ideia de "formação ideológica" (FI). No fundo, essas formações ideológicas são as atitudes e representações que os interlocutores possuem de si mesmos e dos outros que estão envolvidos no processo comunicacional. Obviamente, tudo isso está marcado e sofre a influência do "lugar" social em que esses falantes estão, ou seja, podemos ver evidenciadas aí as relações de poder, subjugação e todos os demais conflitos envolvidos.

Vale ressaltar, a partir da contribuição de Althusser (1974), que essas formações ideológicas não são meras ideias, mas um verdadeiro sistema de práticas sociais que reproduzem as relações de produção. Ou seja, é preciso deixar claro que a ideologia (e, portanto, essas formações sobre as quais nos referimos) possui uma existência material, ou, dizendo de outra forma, materializa-se em distintas materialidades.

Analisar o discurso implica interpretar os sujeitos falando, tendo a produção de sentidos como parte integrante de suas atividades sociais. A ideologia materializa-se no discurso que, por sua vez, é materializado pela linguagem em forma de texto; e/ou pela linguagem não-verbal, em forma de imagens (FERNANDES, 2007, p. 15). 
É a partir dessa constatação que podemos dizer que uma formação ideológica pode reunir várias formações discursivas (FD). Ou seja, uma formação ideológica desdobra-se em distintos enunciados, diferentes entre si, mas ligados à sua matriz. Vejamos um exemplo: no Brasil, por causa de nossa construção histórica, temos uma identidade personalista. Como desdobramento, temos traços (formações discursivas) em nossa cultura de populismo, paternalismo, corrupção, entre outros.

Pêcheux (1995, p. 160) explica isso demonstrando que se pode falar em uma FD a partir de uma FI, "isto é, a partir de uma posição dada numa conjuntura dada, determinada pelo estado da luta de classes, determina o que pode e deve ser dito".

Isso, porém, não se encerra aí. Ao contrário, toda formação discursiva carrega em si outras formações discursivas com as quais se relaciona, ora dialogando, ora entrando em conflito. Assim, um mesmo texto pode apresentar distintas formações discursivas, gerando múltiplas possibilidades de sentidos, sempre de acordo com a posição ocupada por quem enuncia, já que, lembremos, o sentido não é intrínseco ao discurso, mas sofre influências de quem fala, para quem se fala e a partir de qual ideologia se fala.

Assim, para a $\mathrm{AD}$, não podemos falar que o discurso goza de uma constituição homogênea, monolítica, mas, ao contrário, possui um caráter dialógico, ou seja, o sentido do discurso depende das relações que envolvem as formações discursivas, ou seja, o interdiscurso.

A esse respeito, Brandão explica justamente os efeitos desse caráter dialógico do discurso:

por causa do princípio do dialogismo, toda formação discursiva traz dentro de si, outras formações discursivas com que dialoga, contestando, replicando ou aliando-se a elas para dar força a sua fala. Por outro lado, um mesmo enunciado pode aparecer em formações discursivas diferentes, acarretando com isso sentidos diferentes conforme a posição socioideológica de quem fala (BRANDÃO, 2014, p. 08).

Por conseguinte, não podemos falar de um sujeito plenamente livre para enunciar o que quer e da forma que quer. Ao contrário, o sujeito para a $\mathrm{AD}$ é permanentemente interpelado pela formação ideológica que ele ocupa, ou a que está submetido. A partir dos trabalhos psicanalíticos, podemos dizer que o sujeito não é senhor de si e da sua vontade, mas alguém que sofre as investidas de sua formação ideológica em suas distintas formações discursivas, além do seu próprio inconsciente. 
Mussalim e Bentes (2003, p. 137) reforçam a tese de que o sujeito não é livre para dizer o que quer, afinal, "a própria opção do que dizer já é em si determinada pelo lugar que ocupa no interior da formação ideológica à qual está submetido", e ainda que "as imagens que o sujeito constrói ao enunciar só se constituem no próprio processo discursivo".

Levando esses critérios em consideração, podemos dizer que o trabalho do analista do discurso é trazer à luz a historicidade em que está inserido o sujeito do discurso, desnaturalizando as suas formações ideológicas, a fim de que se percebam as formações discursivas que deram origem ao discurso, sendo possível ler os seus sentidos. Segundo Orlandi (2007, p. 96), "para a análise do discurso, não há discurso sem sujeito nem sujeito sem ideologia", e é justamente a ideologia que representa "o efeito de completude que, por sua vez, produz o efeito de 'evidência', sustentando-se sobre o já-dito, os sentidos institucionalizados, admitidos por todos como "natural"'.

É justamente isso que faremos a partir de agora, procurando situar o papa Francisco em sua formação ideológica, sondando as formações discursivas que permeiam os seus discursos, cujo objetivo é oferecer sentido em meio à pandemia que ora nos assola.

\section{O discurso do papa Francisco durante a pandemia}

Os casos de Covid-19 ainda estavam se descortinando para o mundo quando o papa Francisco fez uma rápida menção ao problema, no término da oração do Angelus, no dia 26 de janeiro. Foi a primeira vez que o pontífice se referiu à crise, que até então era localizada:

Desejo estar também próximo e rezar pelas pessoas que estão doentes por causa do vírus que se espalhou na China. Que o Senhor acolha os mortos na Sua paz, conforte as famílias e apoie o grande empenho da comunidade chinesa, já posto em prática para combater a epidemia (FRANCISCO, 2020).

A partir de então, foi possível acompanhar o desenvolvimento do que se tornaria uma pandemia através dos gestos e dos discursos do líder da Igreja Católica Romana, que se tornou uma das vozes de maior alcance durante a crise. Este trabalho, para fins metodológicos, estabeleceu o período de 1 de fevereiro até 18 de maio de 2020 como o lapso temporal que seria pesquisado, já que no dia 31 de janeiro foram notificados os dois primeiros casos de contaminados por Covid-19 na Itália (CORRIERE DELLA SERA, 2020); sendo o dia 18 de maio a data em que as celebrações litúrgicas puderam voltar a ter a participação de fiéis (VATICAN NEWS, 2020). 
Para chegar aos enunciados aqui analisados, utilizamos o site oficial do Vaticano. Nele estão todos os enunciados de Francisco, que por sua função pode se utilizar de distintas maneiras de expressão, dependendo da circunstância. Nossa investigação se deu nessas modalidades de discurso, como o Vaticano as intitula: Angelus e Regina Caele (quando o papa, no domingo, reza e saúda os fiéis na Praça de São Pedro), audiências (acontecem às quartasfeiras, quando ele dirige uma meditação ao povo), cartas (endereçadas a bispos, movimentos populares e fiéis), discursos e mensagens (explanações em geral) e homilias (colocações feitas durante a celebração da missa).

Decidimos não nos debruçar sobre as "meditações matutinas", seção do site do Vaticano em que se disponibilizam os sermões feitos por Francisco nas suas celebrações diárias, na Casa Santa Marta, onde mora. Acreditamos que esses textos possuem características específicas, que merecem ser analisadas de forma apropriada.

Ao todo, finalmente, foram analisados 65 textos. Para este trabalho, focamos naqueles em que o papa usa uma ou mais das seguintes palavras: "epidemia”, "pandemia”, "vírus", "coronavírus", "Covid-19”, "quarentena". Encontramos 25 discursos com essas menções. Porém, apesar de não usar uma dessas palavras no discurso proferido no dia 27 de março, quando houve o momento de oração na Praça de São Pedro, decidimos usar tal pronunciamento devido à sua relevância.

Assim, apresentamos abaixo os textos em que o pontífice aborda diretamente a temática da pandemia, segundo o método aqui utilizado:

\begin{tabular}{l|l} 
MODALIDADES DE DISCURSO & QUANTIDADE \\
\hline Angelus e Regina Caele & 9 \\
Audiências & 7 \\
Cartas & 4 \\
Discursos & 2 \\
Homilias & 2 \\
Mensagem & 1 \\
Momento extraordinário & 1 \\
Tabela 1 Modalidades de discurso do papa Francisco
\end{tabular}

Em primeiro lugar, é importante frisar o que já foi dito anteriormente: acompanhar os discursos do papa durante a pandemia é também perceber como se desenvolveu essa crise sem precedentes. As primeiras menções de Francisco ao vírus ainda se dão diante dos fiéis em uma Praça de São Pedro lotada, quando as medidas de isolamento social não estavam ainda em vigor em Roma.

\footnotetext{
2 Trata-se do momento extraordinário de oração (como foi chamado pelo Vaticano), realizado no dia 27 de março de 2020 .
} 
Prova disso é que no dia 26 de fevereiro, quase um mês depois dos primeiros casos de contaminação na Itália, Francisco (2020) ainda saudava "os fiéis brasileiros da diocese de Valença, as várias comunidades escolares de Portugal vindas de Bragança, Carcavelos, Coimbra e Infias, bem como aos alunos e professores da Academia de Música de Santa Cecília”. A palavra "vindas" não deixa dúvidas de que essas pessoas todas estavam reunidas, e também Francisco estava diante da multidão.

O cenário muda no dia 8 de março, quando agora o pontífice fala às pessoas da biblioteca do Palácio Apostólico, sendo a ocasião transmitida pela internet. Francisco, então, reconhece o momento como "um pouco estranho esta oração do Angelus hoje, com o papa 'fechado' na biblioteca", e explica que se adotou a atitude "para respeitar as medidas precaucionais, a fim de evitar pequenas concentrações de pessoas, que podem favorecer a transmissão do vírus".

Com esses exemplos, queremos demonstrar que as colocações do papa podem contar, sob o ponto de vista católico, como se deu o desenvolvimento da pandemia. No entanto, nosso principal objetivo aqui é demonstrar como Francisco articula duas formações discursivas distintas, mas que dialogam segundo a sua formação ideológica.

\section{Formação Discursiva Religiosa}

Francisco, sendo o papa, ocupa o cargo mais alto na hierarquia católica. Sua missão, segundo a lógica do primus inter paris ${ }^{3}$, é ser sinal da comunhão entre todos os bispos do mundo, bem como o primeiro a defender a inteireza da fé católica. Assim, é possível concluir que sua principal tarefa é manter a fidelidade doutrinária, bem como fortalecer a unidade entre todos os católicos, algo que poderá ser encontrado em seus discursos durante a pandemia.

De fato, é possível dizer que ele procura fazer uma leitura espiritual do que acontece, oferecendo critérios religiosos de compreensão da realidade e de resposta a essa mesma realidade; nesse caso, bastante difícil. É possível perceber isso especialmente no Angelus, nas audiências e nas homilias.

Para ser legível pelos católicos, o primeiro movimento que Francisco realiza em seus discursos é aquele religioso, espiritual. Para isso, ele procura articular em suas colocações os sentidos da formação ideológica católica, através da menção a Jesus Cristo, de Maria e dos santos.

\footnotetext{
${ }^{3}$ Significa, em tradução literal, "primeiro entre iguais".
} 
Isso pode ser observado no dia 27 de março, quando acontece o "momento extraordinário de oração em tempo de pandemia”. Naquela ocasião, diante da Praça de São Pedro vazia, o papa conduz um breve, porém significativo ato, transmitido para milhões de pessoas em tempo real. Ali, antes mesmo das palavras, os símbolos usados pela igreja de Roma denotam a relevância da memória discursiva.

Antes de tudo, é preciso mencionar a escolha do crucifixo que foi posto defronte à basílica de São Pedro. Tratava-se da imagem que, segundo a tradição católica, foi levada por todas as ruas de Roma durante uma epidemia que assolou a cidade no século XVI. Segundo os relatos da época, após a travessia, as mortes cessaram e se entendeu aquilo como intervenção divina.

Ao lado do crucifixo estava um antigo ícone mariano que, também segundo a tradição da Igreja, foi desenhado por São Lucas, autor de um dos evangelhos cristãos. A obra se chama Sálus Pópuli Románi, significa "salvação do povo romano", e também ela está envolvida em relatos de milagres.

Se é verdade que nessas imagens é possível perceber a formação discursiva religiosa do papa, é sobretudo em seu discurso daquele dia que isso fica mais perceptível. Francisco, naquela tarde, fará uma relação entre a crise do novo coronavírus com o relato evangélico da tormenta que é acalmada por Jesus. Utilizando-se de recursos linguísticos, o papa, por exemplo, compara o momento vivido pelo mundo com o entardecer do capítulo 4 do evangelho de Marcos:

Desde há semanas que parece o entardecer, parece cair a noite. Densas trevas cobriram as nossas praças, ruas e cidades, apoderaram-se das nossas vidas, enchendo tudo dum silêncio ensurdecedor e um vazio desolador, que paralisa tudo à sua passagem: pressente-se no ar, nota-se nos gestos, dizem-no os olhares. Revemo-nos temerosos e perdidos (FRANCISCO, 2020).

A partir daí, o pontífice propõe que a humanidade se reveja na narrativa, ou seja, ele articula os sentidos religiosos com a realidade que se está vivendo. Um outro exemplo disso se dá durante a homilia na festa da Divina Misericórdia. Ali, Francisco (2020) relaciona a maneira como os primeiros cristãos viveram com a necessidade de repensar a lógica do mundo atual: "naquela comunidade, depois da ressureição de Jesus, apenas um ficara para trás e os outros esperaram por ele. Hoje parece dar-se o contrário: uma pequena parte da humanidade avançou, enquanto a maioria ficou para trás".

Até aqui, como é possível perceber, o pontífice se restringe aos sentidos estritamente católicos, ou seja, dentro dos cânones de sua formação ideológica católica, ou da sua posição- 
sujeito "papa". Mas, como vimos anteriormente, uma formação discursiva não é um bloco homogêneo e monolítico, mas comporta distintas formações discursivas.

Dizendo de outra forma, o papel do analista do discurso é descrever as dispersões do texto, ou seja, as suas heterogeneidades, ou, como explicam Mussalim e Bentes (2003), a ideia de que uma "FD é um espaço atravessado por outras FDs, ela não pode ser concebida como formada por elementos ligados entre si por um princípio de unidade. É nesse sentido que Foucault a concebe como uma dispersão."

Isso se verifica no discurso de Francisco quando ele desloca o sentido do seu discurso para além dos fiéis católicos, quando ele, por exemplo, convida para que no dia 25 de março "todos os chefes das Igrejas e os líderes de todas as comunidades cristãs, juntamente com todos os cristãos das várias confissões, a invocar o Deus Altíssimo e Todo-Poderoso, recitando ao mesmo tempo a oração que Jesus [...] nos ensinou". Aqui, o papa, apesar de alargar a sua formação discursiva, ainda permanece dentro dos limites da FD cristã.

Porém, no dia 3 de maio, Francisco deslocará com mais força a sua FD religiosa, colocando-a em diálogo com formações ideológicas não-cristãs:

aceitei a proposta do Alto Comitê para a Fraternidade Humana a fim de que, no próximo dia 14 de maio, os crentes de todas religiões se unam espiritualmente num dia de oração, jejum e obras de caridade, para implorar a Deus que ajude a humanidade a superar a pandemia do coronavírus [...] todos os crentes juntos, crentes de diferentes tradições (FRANCISCO, 2020).

Através desses exemplos, podemos perceber que Francisco, como papa, procura mobilizar, antes de tudo, em seus discursos, um caráter espiritual, próprio de quem ocupa a posição-sujeito em que ele está. Sua formação ideológica católica o situa em formações discursivas religiosas. Essas, por sua vez, apesar de serem fundamentalmente católicas, também sofrem deslocamentos, dialogando com convicções de outras confissões cristãs (ecumenismo) e mesmo de outras convicções religiosas (diálogo inter-religioso).

\section{Formação Discursiva Política ${ }^{4}$}

Como vimos, a principal formação discursiva do papa é aquela religiosa. Porém, explicitaremos a partir de agora um outro aspecto muito importante para entender os discursos mobilizados por Francisco: a sua formação discursiva política. De fato, acompanhar os textos

\footnotetext{
${ }^{4}$ Sabemos que uma formação discursiva é sempre atravessada por sentidos e saberes de outras formações discursivas. A nomeação aqui utilizada (formação discursiva política) é puramente didática.
} 
aqui analisados é perceber uma profunda preocupação com os desdobramentos políticos, econômicos e sociais da pandemia da Covid-19, especialmente daqueles que envolvem uma população já marcada pela vulnerabilidade.

O líder católico, em seus pronunciamentos, vai descortinando as contradições estruturais, reveladas pela crise, e propõe na mensagem Urbi et $\mathrm{Orbi}^{5}$ uma verdadeira análise do mundo atual que, segundo ele, precisa desvencilhar-se da indiferença, dos egoísmos e das divisões (FRANCISCO, 2020).

A fim de apresentarmos uma visão mais ampla da formação discursiva política do papa, decidimos demonstrá-la através dos interlocutores a quem Francisco (2020) se dirige em seus pronunciamentos; trata-se de "médicos, enfermeiros e enfermeiras, trabalhadores dos supermercados, pessoal da limpeza, curadores, transportadores, forças policiais, voluntários, sacerdotes, religiosas e muitos - mas muitos - outros". Como se pode perceber, os sujeitos a quem o papa se refere dão uma clara demonstração de que seu discurso é realmente permeado por uma formação discursiva política e, dentro dela, por distintos interlocutores. De forma geral, esses podem ser demonstrados nos seguintes grupos:

1. Vítimas e familiares;

2. Autoridades políticas econômicas;

3. Profissionais essenciais;

4. Movimentos populares e de trabalhadores;

5. Pobres e vulneráveis.

A seguir, mostraremos alguns exemplos da formação discursiva política do papa através da menção aos grupos acima apresentados.

\section{As vítimas da pandemia e suas famílias}

O primeiro interlocutor a quem o pontífice se dirige são as pessoas infectadas pela pandemia, as vítimas fatais e seus familiares. Na verdade, em quase todas as mensagens aqui analisadas é possível ver que a primeira referência feita pelo papa é sempre em relação às vítimas, sua preocupação é que "o povo não se sinta abandonado", e justamente por isso agradece àqueles sacerdotes "criativos", que "pensam em muitas maneiras de estar próximos

\footnotetext{
5 A benção urbi et orbi significa "à cidade e ao mundo", sendo concedida na Páscoa e no Natal. No caso aqui relatado, trata-se do dia 12 de abril, domingo de Páscoa.
} 
do povo". Esse desejo de solidariedade é representado "no desejo de manifestar mais uma vez a minha proximidade aos doentes de coronavírus".

É justamente com esse intuito que Francisco fará uma ligação telefônica para um programa $^{6}$ ao vivo da rede de televisão Rai, em 10 de abril. Na ocasião, sem que se esperasse, a apresentadora fica surpresa ao perceber que está conversando com o papa, que afirma estar “perto, muito perto de vocês [...] do que mais sofre, especialmente das vítimas desta pandemia, da dor do mundo, mas olhando para cima, olhando para a esperança, porque a esperança não decepciona. Não tira a dor, mas não decepciona” (FRANCISCO, 2020).

\section{As autoridades políticas e econômicas}

Se para o grupo anterior a mensagem do papa é mais unânime, ligada à solidariedade, para as autoridades políticas e econômicas é possível perceber uma certa mudança de tom. Nas primeiras referências a eles, o papa demonstra "proximidade às autoridades que devem tomar medidas duras, mas para o nosso bem”. E, ainda mais, faz eco às recomendações dos órgãos internacionais para que se "retome as atividades diárias habituais" apenas quando "as circunstâncias o permitam" (FRANCISCO, 2020).

Porém, é possível perceber que, com o passar do tempo, Francisco desloca o seu discurso da "proximidade" para também o da reflexão. É justamente aqui que ele fará as menções mais contundentes sobre uma sociedade de avanços, "destemidos, pensando que continuaríamos sempre saudáveis num mundo doente" (FRANCISCO, 2020). E segue: com a tempestade, caiu a maquiagem dos estereótipos com que mascaramos o nosso 'eu' sempre preocupado com a própria imagem; e ficou a descoberto [...] aquela abençoada pertença comum a que não nos podemos subtrair: a pertença como irmãos”.

Por isso, pensando nas contradições sociais que ficaram à mostra por causa da pandemia, o papa pede que "todas as pessoas que detêm responsabilidades políticas a trabalhar ativamente em prol do bem comum dos cidadãos, fornecendo os meios e instrumentos necessários para permitir a todos que levem uma vida digna”. Francisco continua, pedindo medidas específicas diante das circunstâncias:

sejam abrandadas também as sanções internacionais que impedem os países visados de proporcionar apoio adequado aos seus cidadãos e seja permitido a todos os Estados acudir às maiores necessidades do mundo atual, reduzindo -

\footnotetext{
${ }^{6}$ Trata-se do programa A sua immagine, um dos mais importantes da TV italiana.
} 
se não mesmo perdoando - a dívida que pesa sobre os orçamentos dos mais pobres (FRANCISCO, 2020).

Em relação aos conflitos internacionais, o pontífice pede coragem das autoridades para aderirem "ao apelo a um cessar-fogo global e imediato [...]. Este não é tempo para continuar a fabricar e comercializar armas, gastando somas enormes que deveriam ser usadas para cuidar das pessoas e salvar vidas" (FRANCISCO, 2020). E conclui: “oxalá mexa conosco dentro o que está a acontecer: é tempo de remover as desigualdades, sanar a injustiça que mina pela raiz a saúde da humanidade inteira".

Esses são alguns dos casos em que pudemos observar que o discurso do papa interpela diretamente aqueles que estão revestidos de responsabilidade política e econômica, a quem "exorto a serem sensíveis a este grave problema e a tomarem as medidas necessárias para evitar tragédias futuras".

Vale ressaltar ainda que Francisco criou durante a pandemia uma comissão específica para debater os desafios ligados ao problema, durante e depois da crise. O grupo é liderado pelo Dicastério para o Serviço do Desenvolvimento Humano Integral, órgão do Vaticano, com cinco comitês de trabalho, articulados com iniciativas de todo o mundo.

\section{Profissionais de serviços essenciais}

O terceiro grupo de interlocutores a quem o papa se dirige é aqueles dos profissionais de serviços essenciais, especialmente dos médicos e enfermeiros, "que por todo o lado oferecem um testemunho de solicitude e amor ao próximo até ao extremo das forças e, por vezes, até ao sacrifício da própria saúde" (FRANCISCO, 2020). O papa recorda sobretudo das "mulheres médicas, enfermeiras, agentes da polícia e das prisões, empregadas de lojas de bens de primeira necessidade".

Ainda ligado à questão do Covid-19 em si, o papa menciona os cientistas, unidos “de forma transparente e desinteressada, para encontrar vacinas e tratamentos e garantir o acesso universal a tecnologias essenciais que permitam que pessoas contagiadas, em todas as partes do mundo, recebam os cuidados de saúde necessários".

Francisco (2020) vai adiante e dirige uma carta aos profissionais da comunicação, especialmente aqueles que trabalham "nos jornais de rua, em especial, os seus vendedores, na sua maioria desabrigados [...], desempregados: milhares de pessoas em todo o mundo vivem [...] graças à venda destes jornais extraordinários”. Proximidade é também o que o papa 
explicita "aos policiais, aos soldados que procuram manter a ordem nas ruas, para que seja cumprido o que o governo nos pede para o bem de todos. Proximidade a todos”.

Referindo-se a esses profissionais de serviços essenciais, o pontífice escreve para os jovens, durante a Jornada Mundial da Juventude, que esses são "os verdadeiros heróis que vêm à luz nestes dias: não são aqueles que têm fama, dinheiro e sucesso, mas aqueles que se oferecem para servir os outros".

\section{Movimentos populares e de trabalhadores}

Entre as cartas publicadas pelo papa, uma delas chama a atenção de imediato, aquela enviada aos movimentos populares. É bastante representativo da FD política de Francisco que ele destine um de seus discursos, durante uma pandemia sem precedentes, aos grupos que articulam as mobilizações de trabalhadores. Trata-se de um longo artigo em que o pontífice apresenta os principais problemas que envolvem o cotidiano dessas pessoas, "que muitas vezes não são reconhecidos adequadamente porque, para este sistema, são verdadeiramente invisíveis. As soluções do mercado não chegam às periferias e a presença protetora do Estado é escassa".

É justamente a esses "invisíveis" sociais que o papa faz um deslocamento da sua posição-sujeito. É comum, dentro da memória e do imaginário coletivo, não questionar a sabedoria e o conhecimento do líder da Igreja Católica. Porém, falando aos movimentos populares, Francisco diz que são justamente eles que não ficam na denúncia, mas "arregaçam as mangas e continuam a trabalhar para suas famílias, seus bairros, para o bem comum. Essa atitude de vocês me ajuda, questiona e ensina muito".

É também muito significativo que nesta carta Francisco passe a usar uma expressão que será uma constante em seus pronunciamentos: "pensar no depois". Ou seja, refletir e articular iniciativas que procurem apresentar novos caminhos para a construção do bem comum. Chama a atenção, inclusive, nesta mesma carta, que o papa proponha "pensar em um salário universal que reconheça e dignifique as tarefas nobres e insubstituíveis que vocês realizam; capaz de garantir e tornar realidade esse slogan tão humano e tão cristão: nenhum trabalhador sem direitos".

A proposta está em consonância com as reinvindicações feitas por esses trabalhadores durante os encontros que Francisco teve com os movimentos sociais no Vaticano e em Santa Cruz de la Sierra, em anos anteriores, quando eles pediram terra, comida, teto e trabalho.

O papa, não mais na carta anteriormente mencionada, mas em audiência geral, na biblioteca do palácio apostólico, explica que "ficou impressionado" com os relatos dos 
trabalhadores agrícolas, entre eles imigrantes, demonstrando, mais uma vez, a sua forte relação com os problemas sociais.

Infelizmente, muitos são extremamente explorados. É verdade que a atual crise afeta a todos, mas a dignidade das pessoas deve sempre ser respeitada. É por isso que acrescento a minha voz ao apelo desses trabalhadores e de todos os trabalhadores explorados. Que esta crise nos dê a oportunidade de tornar a dignidade da pessoa e a dignidade do trabalho o centro da nossa preocupação (FRANCISCO, 2020).

\section{Pobres e vulneráveis}

Por fim, porém não menos importante, o grupo a quem o papa se dirige é aquele formado pelos pobres e mais vulneráveis. De fato, é possível dizer que esses são, ao lado das vítimas da Covid-19, os destinatários mais frequentes das mensagens papais, especialmente "os mais pobres e os desabrigados", aqueles "que foram excluídos dos benefícios da globalização". Lembra, então, das "mulheres, que multiplicam o pão nos refeitórios comunitários, cozinhando com duas cebolas e um pacote de arroz um delicioso guisado para centenas de crianças".

Especificamente sobre as mulheres, o papa recorda daquelas que se "encontram fechadas nas suas casas [...]. Por vezes, correm o risco de serem sujeitas à violência, por uma coabitação da qual carregam um fardo demasiado pesado". Ainda sobre a condição de tantas pessoas que vivem a própria vulnerabilidade em casa, recorda "dos lares de idosos, dos quarteis". E segue explicando que "gostaria de mencionar as pessoas nas prisões. Li um memorando oficial da Comissão de Direitos Humanos que fala sobre o problema das prisões superlotadas, o que se pode tornar uma tragédia”.

Esses são alguns exemplos de como Francisco lança o seu olhar sobre as pessoas marcadas pela vulnerabilidade e sugere um caminho a ser trilhado:

O drama que estamos a atravessar neste período impele-nos a levar a sério o que é sério, a não nos perdermos em coisas de pouco valor; a redescobrir que a vida não serve se não se serve. Porque a vida mede-se pelo amor. [...] procuremos contactar quem sofre, quem está sozinho e necessitado. Não pensemos só naquilo que nos falta; pensemos no bem que podemos fazer (FRANCISCO, 2020).

\section{Considerações finais}

Iniciamos este trabalho demonstrando, através da Análise do Discurso de linha francesa, que todo discurso é marcado por sua historicidade, ou seja, carrega as influências do seu 
contexto. Além disso, vimos que é preciso conhecer o sujeito do discurso, mas sobretudo a sua formação ideológica que se materializa no que é dito.

Ainda mais: vimos que toda formação ideológica dá origem a formações discursivas, que estarão presentes justamente nos traços encontrados no texto. Só assim é possível aproximar-se do sentido daquele discurso, ou de um de seus sentidos.

A partir do que apresentamos aqui, acreditamos ser possível afirmar que o papa Francisco está dentro daquilo que se poderia chamar de formação ideológica católica, ou seja, é daí que parte as suas noções e interpretações da realidade, a sua forma específica, inclusive, de se colocar diante da realidade. Essa FI católica se desdobra em duas formações discursivas distintas, porém, no discurso papal, conciliáveis: a FD religiosa e a FD política.

Na primeira, sobressaem os sentidos estritamente espirituais, aqueles ligados à fé, aos ritos e imagens católicos, ancorados em figuras como Jesus e Maria. É perceptível que a primeira ocupação de Francisco em seus discursos é fazer justamente uma leitura espiritual da crise da Covid-19, oferecendo chaves de leitura para compreensão da pandemia.

Porém, ao mesmo tempo, é claramente presente uma FD política no discurso do pontífice, e isso fica bastante evidente nos interlocutores a quem destina os seus pronunciamentos. Aqui, demos atenção aos seguintes grupos: vítimas e familiares da pandemia, autoridades políticas e econômicas, profissionais de serviços essenciais, movimentos populares e de trabalhadores, além de pobres e vulneráveis.

Em todos esses casos, a intenção de Francisco é permanentemente chamar a atenção do mundo para as contradições das estruturas políticas e econômicas que, segundo ele, nem sempre estão preocupadas com o bem comum e, por isso, acabam reforçando as desigualdades que ficaram à mostra durante a crise.

É importante frisar que os dados aqui encontrados reforçam a visão que o papa tem da realidade. Para ele, ao contrário, do que se poderia imaginar, a realidade não pode ser definida de uma única forma, nem mesmo de forma circular.

O modelo é o poliedro, que reflete a confluência de todas as partes que nele
mantêm a sua originalidade. Tanto a ação pastoral como a ação política
procuram reunir nesse poliedro o melhor de cada um. Ali entram os pobres
com a sua cultura, os seus projetos e as suas próprias potencialidades. Até
mesmo as pessoas que possam ser criticadas pelos seus erros têm algo a
oferecer que não se deve perder. [...] é a totalidade das pessoas em uma
sociedade que procura um bem comum, que verdadeiramente incorpore a
todos (FRANCISCO, 2019, p. 131). 
A noção de poliedro corresponde bem à análise que aqui foi desenvolvida. Francisco articula dentro da mesma FI católica duas FDs aparentemente contrárias, como dissemos anteriormente. Nesse sentido, o discurso e a visão poliédrica da realidade que o papa tem se relaciona com a teorização que a Análise do Discurso faz sobre a heterogeneidade do discurso, que segundo Mussalim e Bentes (2003, p. 131) o “impede de ser um espaço 'estável', 'fechado', 'homogêneo', mas não o redime de estar inserido em um espaço controlado, demarcado pelas possibilidades de sentido que a formação ideológica pela qual é governado lhe concede”.

Concluindo este artigo, não desejamos encerrar a discussão sobre o discurso papel durante a pandemia, ao contrário. Na realidade, enquanto desenvolvíamos nossa pesquisa, encontrávamos novas possibilidades de investigação, e é justamente assim que desejamos encerrar esta nossa contribuição: incentivando novas análises sobre o momento pandêmico, que revelou a necessidade de repensarmos os caminhos da humanidade.

\section{REFERÊNCIAS}

ALTHUSSER, L. Ideologia e aparelhos ideológicos do estado. Tradução de J. J. Moura Ramos. Lisboa, Presença/Martins Fontes, 1974.

BERGER, Peter L.; LUCKMANN, Thomas. A construção social da realidade: tratado da sociologia do conhecimento. 31. ed. Tradução de Floriano de Souza Fernandes. Petrópolis, Vozes, 2009.

BRANDÃO, Helena H. Nagamine. Introdução à Análise do Discurso. Campinas, SP: Editora UNICAMP, 2014.

CORRIERE DELLA SERA. Coronavirus, primi due casi in Italia. Milão, 2020. Disponível em: <https://www.corriere.it/cronache/20_gennaio_30/coronavirus-italia-corona-9d6dc4364343-11ea-bdc8-faf1f56f19b7.shtml>. Acesso em: 26 de maio de 2020.

FERNANDES, Cleudemar Alves. Análise do discurso: reflexões introdutórias. 2. ed. São Carlos: Claraluz, 2007.

FRANCISCO. Angelus. Cidade do Vaticano, 2020. Disponível em: <http://w2.vatican.va/content/francesco/pt/angelus/2020/documents/papafrancesco_angelus_20200126.html>. Acesso em: 26 de maio de 2020.

FRANCISCO. Angelus. Cidade do Vaticano, 2020. Disponível em: <http://w2.vatican.va/content/francesco/pt/angelus/2020/documents/papafrancesco_angelus_20200308.html>. Acesso em: 24 de maio de 2020.

FRANCISCO. Angelus. Cidade do Vaticano, 2020. Disponível em: $<$ http://w2.vatican.va/content/francesco/pt/audiences/2020/documents/papafrancesco_20200226_udienza-generale.html>. Acesso em: 27 de maio de 2020.

FRANCISCO. Momento extraordinário de oração em tempo de epidemia. Cidade do Vaticano, 2020. Disponível em: $<$ http://w2.vatican.va/content/francesco/pt/homilies/2020/documents/papafrancesco_20200327_omelia-epidemia.html>. Acesso em: 27 de maio de 2020. 
FRANCISCO. Santa Missa da Divina Misericórdia. Cidade do Vaticano, 2020. Disponível em: <http://w2.vatican.va/content/francesco/pt/homilies/2020/documents/papafrancesco_20200419_omelia-divinamisericordia.html>. Acesso em: 27 mai. 2020. FRANCISCO. Angelus. Cidade do Vaticano, 2020. Disponível em: <http://w2.vatican.va/content/francesco/pt/angelus/2020/documents/papafrancesco_angelus_20200322.html>. Acesso em: 27 mai. 2020.

FRANCISCO. Regina Caele. Cidade do Vaticano, 2020. Disponível em: < http://w2.vatican.va/content/francesco/pt/angelus/2020/documents/papa-francesco_reginacoeli_20200503.html >. Acesso em: 27 mai. 2020.

FRANCISCO. Mensagem Urbi et Orbi do papa Francisco. Cidade do Vaticano, 2020. Disponível em: < http://w2.vatican.va/content/francesco/pt/messages/urbi/documents/papafrancesco_20200412_urbi-et-orbi-pasqua.html>. Acesso em: 27 mai. 2020.

FRANCISCO. Llamada telefónica en directo del papa Francisco al programa de la Rai "A sue immagine". Cidade do Vaticano, 2020. Disponível em:

<http://w2.vatican.va/content/francesco/es/speeches/2020/april/documents/papafrancesco_20200410 telefonata-asuaimmagine.html>. Acesso em 28 mai. 2020.

FRANCISCO. Angelus. Cidade do Vaticano, 2020. Disponível em: <http://w2.vatican.va/content/francesco/pt/angelus/2020/documents/papafrancesco_angelus_20200322.html>. Acesso em 28 mai. 2020.

FRANCISCO. Carta do papa Francisco aos jornais de rua. Cidade do Vaticano, 2020. Disponível em: <http://w2.vatican.va/content/francesco/pt/letters/2020/documents/papafrancesco_20200421_lettera-giornali-distrada.html>. Acesso em 28 mai. 2020.

FRANCISCO. Celebração do domingo de ramos e da paixão do Senhor. Cidade do Vaticano, 2020. Disponível em:

<http://w2.vatican.va/content/francesco/pt/homilies/2020/documents/papafrancesco_20200405_omelia-palme.html>. Acesso em 28 mai. 2020.

FRANCISCO. Carta do papa Francisco aos movimentos populares. Cidade do Vaticano, 2020. Disponível em:

<http://w2.vatican.va/content/francesco/pt/letters/2020/documents/papafrancesco_20200412_lettera-movimentipopolari.html>. Acesso em 28 mai. 2020.

FRANCISCO. Evangelii Gaudium. Tradução de Conferência Nacional dos Bispos do Brasil. São Paulo: Paulus, 2019.

LÉVY, Pierre. Cibercultura. Tradução de Carlos Irineu da Costa. São Paulo: Editora 34, 2010.

MUSSALIM, Fernanda; BENTES, Anna Christina. Introdução à linguística: domínios e fronteiras, v. 2. 3. ed. São Paulo: Cortez, 2003.

ORLANDI, Eni Puccinelli. As formas do silêncio: no movimento dos sentidos. 6 ed.

Campinas, SP: Editora da UNICAMP, 2007.

PÊCHEUX, Michel. Semântica e discurso: uma crítica à afirmação do óbvio. Tradução de Eni Pulcinelli Orlandi. 2.ed. Campinas, SP: Editora da UNICAMP, 1995.

PÊCHEUX, Michel. Papel da memória. In: ACHARD, P. et al. (Org.). Papel da memória. Tradução de José Horta Nunes. Campinas: Pontes, 1999.

VATICAN NEWS. Agora é oficial: missas com participação de fiéis na Itália a partir de 18 de maio. Cidade do Vaticano, 2020. Disponível em:

<https://www.vaticannews.va/pt/igreja/news/2020-05/coronavirus-retomadas-missas-comfieis-na-italia-cei-governo.html >. Acesso em: 26 mai. 2020. 